\title{
Pulmonary Vasculitis
}

\author{
Kevin K. Brown \\ Pulmonary Division, Department of Medicine, National Jewish Medical and Research Center; and Division of Pulmonary Sciences and Critical \\ Care Medicine, Department of Medicine, University of Colorado Health Sciences Center, Denver, Colorado
}

\begin{abstract}
Pulmonary vasculitis describes a number of distinct disorders that are pathologically characterized by the destruction of blood vessels. The clinical manifestations of each disorder are defined by the size, type, and location of the affected vasculature. The clinical approach to these disorders rests upon an astute clinician considering the diagnosis and identifying the specific patterns of clinical, radiologic, laboratory, and pathologic abnormalities. Lung involvement is most commonly seen with the primary, idiopathic, small-vessel, or antineutrophil cytoplasmic antibody-associated vasculitides; Wegener's granulomatosis, microscopic polyangiitis, and Churg-Strauss syndrome. However, primary, idiopathic medium and large-vessel vasculitis, primary immune complex-mediated vasculitis, and secondary vasculitis are all capable of presenting with lung involvement. In this article, we focus on the more common, antineutrophil cytoplasmic antibody-associated disorder, vasculitides.
\end{abstract}

Keywords: Churg-Strauss syndrome; microscopic polyangiitis; vasculitis; Wegener's granulomatosis

The diagnosis and management of a systemic vasculitis is among the most demanding challenges in clinical medicine. The disorders themselves are rare, with an incidence of 20 to 100 cases/ million and a prevalence of 150 to 450 /million (1-3). Their signs and symptoms are nonspecific and overlap with infections, connective tissue diseases, and malignancies. The presentation of any given disease is highly variable; only rarely does a patient present with all of the "classic" findings. This combination makes delays in diagnosis common. In patients with a known vasculitis who clinically deteriorate, identifying the cause can be equally as difficult because activity of the underlying disease, a complication of drug therapy, overwhelming infection, or a combination of all three may present in the same fashion. Despite these obstacles, the astute clinician can make the diagnosis and minimize the complications associated with management by keeping some broad concepts in mind.

Vasculitis can be pathologically defined by the presence of cellular inflammation, vessel destruction, and tissue necrosis. The characteristics of the inflammation can be helpful in determining the underlying diagnosis, and granulomatous, eosinophilic, lymphoplasmacytic, or neutrophilic patterns can be seen. The clinical features of each disease are determined by the site, size, and type of vessel involved and by the relative amounts of inflammation, vessel destruction, and tissue necrosis.

Even classifying a vasculitis is challenging, and the criteria currently used are relatively insensitive and nonspecific as diagnostic tools. Thus, the diagnosis of vasculitis relies on the astute clinician recognizing combinations of particular clinical, laboratory, radiologic, and pathologic features. The major clinical bene-

(Received in original form November 17, 2005; accepted in final form December 2, 2005) Supported by NHLBI SCOR HL67671.

Correspondence and requests for reprints should be addressed to Kevin K. Brown, M.D., National Jewish Medical and Research Center, 1400 Jackson Street, Denver, CO 80206. E-mail: brownk@njc.org

Proc Am Thorac Soc Vol 3. pp 48-57, 2006

DOI: $10.1513 /$ pats.200511-120JH

Internet address: www.atsjournals.org fit of classifying these disorders is to provide a framework that allows an appreciation of the presenting features of disease. To this end, most current classification schemes are based on clinicopathologic features rather than etiology (Table 1). Using this approach, classification by vessel size (small, medium, and large) is useful in suggesting clinical features associated with a particular disease. The large vessels include the aorta and its largest branches (clinically affecting the extremities and head/neck). The medium-sized vessels refer to the main visceral arteries (e.g., renal, hepatic, coronary, mesenteric). The small vessels refer to the capillaries, venules, and arterioles. Some of the small- and large-vessel vasculitides may involve medium-sized arteries, but large- and medium-vessel vasculitides generally do not involve vessels smaller than arteries. The primary small-vessel vasculitides are also known as the antineutrophil cytoplasmic antibody (ANCA)-associated vasculitides and include Wegener's granulomatosis (WG), Churg-Strauss syndrome (CSS), and microscopic pulmonary angiitis (MPA). Isolated pauci-immune pulmonary capillaritis and idiopathic pauci-immune rapidly progressive glomerulonephritis (RPGN) due to vasculitis can be considered as organ-specific subsets of MPA.

\section{MAKING THE INITIAL DIAGNOSIS}

The importance of a detailed initial history and examination of the patient with suspected vasculitis cannot be overemphasized. Close attention must be paid to seemingly unrelated signs and symptoms because vasculitis and its mimics can present with a variety of multisystem manifestations. Although the clinical presentation of any given disease can be highly variable, the identification of particular combinations of findings, or clinical scenarios, should suggest the possibility of vasculitis (4).

\section{Clinical Scenarios Suggestive of Vasculitis}

Diffuse alveolar hemorrhage. Diffuse alveolar hemorrhage (DAH) can be defined by the presence of hemoptysis, diffuse alveolar infiltrates, and a drop in hematocrit. However, up to one-third of patients do not have hemoptysis, the alveolar infiltrates can be unilateral, and a drop in hematocrit or hemoglobin can be difficult to document. Therefore, DAH must be considered in patients with otherwise unexplained alveolar infiltrates (Figure 1), particularly when seen with a connective tissue disease, bone marrow transplantation, chemotherapy, or new-onset renal insufficiency (5). DAH can be diagnosed with bronchoalveolar lavage (BAL) because serially aspirated aliquots of fluid reveal a persistently bloody return. The diagnosis can also be suggested by an increase in the diffusion capacity of more than $30 \%$ over baseline. The differential diagnosis of DAH includes diseases associated with the pathologic finding of capillaritis (a cellular infiltrate of neutrophils in the capillaries and venules; Figure 1) and those associated with normal vessels, or bland hemorrhage (Table 2). The ANCA-associated vasculitides that present with DAH generally have capillaritis identified on surgical lung biopsy. However, when partially treated, only bland hemorrhage may be seen. The finding of pulmonary capillaritis in the absence of an associated systemic vasculitis is termed idiopathic pauciimmune pulmonary capillaritis. This disorder is classified within 


\section{TABLE 1. CLASSIFICATION OF THE VASCULITIDES}

Primary idiopathic vasculitis
Small vessel
Wegener's granulomatosis
Churg-Strauss syndrome
Microscopic polyangiitis
Idiopathic pauci-immune rapidly progressive glomerulonephritis
Isolated pauci-immune pulmonary capillaritis
Medium vessel
Polyarteritis nodosa
Kawasaki disease
Large vessel
Giant cell arteritis
Takayasu's arteritis
Primary immune complex-mediated vasculitis
Goodpasture's syndrome
Henoch-Schönlein purpura
Behçet's disease
IgA nephropathy
Secondary vasculitis
Classic autoimmune disease
Systemic lupus erythematosus
Rheumatoid arthritis
Polymyositis/dermatomyositis
Scleroderma
Antiphospholipid antibody syndrome
Essential cryoglobulinemia
Inflammatory bowel disease
Hypocomplementemic urticarial vasculitis
Drug-induced (e.g., propylthiouracil, diphenylhydantoin)
Paraneoplastic
Infection

Among the primary vasculitides, those that affect the small vessels, Wegener's granulomatosis, Churg-Strauss syndrome, and microscopic polyangiitis, are grouped together as the ANCA-associated vasculitides. The vasculitides associated with pathologic granulomata include Wegener's granulomatosis, Churg-Strauss syndrome, Takayasu arteritis, and giant cell arteritis.

the family of idiopathic, small-vessel vasculitis, despite generally being ANCA negative (6).

Acute glomerulonephritis. RPGN is identified by an elevated blood urea nitrogen and serum creatinine and by active urinary sediment (i.e., hematuria [especially with dysmorphic red cells], red cell casts, and proteinuria [ $>500 \mathrm{mg} / \mathrm{d}]$ ). Although RPGN is present in only $5 \%$ of patients presenting with renal insufficiency, these cases must be distinguished from the more common causes given the differences in therapy and outcome. Once RPGN is identified, the differential diagnosis includes the ANCA-associated vasculitides, idiopathic pauci-immune glomerulonephritis, systemic lupus erythematosus (SLE), Goodpasture's syndrome, postinfectious glomerulonephritis, IgA nephropathy, HenochScholein purpura, essential cryoglobulinemia, and membranoproliferative glomerulonephritis (7).

Pulmonary-renal syndrome. Pulmonary-renal syndrome refers to patients with DAH (or pathologic pulmonary capillaritis) and glomerulonephritis. However, whenever a destructive upper or lower airway lesion occurs with renal insufficiency, vasculitis should be considered. The differential includes the ANCAassociated vasculitides, Goodpasture's syndrome, and SLE.

Destructive upper airway lesions. Otherwise unexplained chronic refractory sinusitis, epistaxis, otitis, significant ulcerative, or destructive soft tissue or bony lesions should lead one to consider vasculitis.

Chest imaging findings of cavitary or nodular disease. Like the clinical features, there are a wide variety of nonspecific abnormalities that may be seen on chest imaging. The presence of otherwise unexplained nodular or cavitary disease should raise one's suspicion for vasculitis. Although infection and malignancy are the most common explanations, in the correct clinical setting vasculitis, particularly ANCA-associated vasculitis, should be strongly considered. Nodular disease is found in 55 to $70 \%$ and cavitary disease in 35 to $50 \%$ of patients with WG $(8,9)$.

Palpable purpura. The finding of palpable purpura on physical examination implies a small-vessel, cutaneous vasculitis (10). Although a cutaneous (hypersensitivity) vasculitis secondary to a drug reaction is the most common explanation, the ANCAassociated vasculitides, cryoglobulinemia, connective tissue diseases, infections, and malignancy should be considered.

Mononeuritis multiplex. A wide variety of central or peripheral nervous system manifestations may occur in the vasculitides. In particular, the presence of mononeuritis multiplex should raise concern $(11,12)$. Although mononeuritis multiplex is defined by the occurrence of abnormalities in two or more peripheral nerve distributions, the development of findings in even a single nerve distribution, such as the sudden onset of a foot or wrist drop, can be the result of a vasculitis. Other presentations include pain, numbness, paresthesias, weakness, or loss of function.

Multisystem disease. Unusual combinations of signs and symptoms that involve multiple organ systems simultaneously or over time should raise the suspicion of a vasculitis. This requires a high index of suspicion from the clinician. Minor clinical complaints, such as remote or intermittent constitutional symptoms, unusual "rashes," arthritis, or "chronic sinus disease," gain relevance when new findings occur, such as an abnormal chest $\mathrm{X}$-ray, shortness of breath, or renal failure.

\section{SPECIFIC TESTING}

\section{ANCA Antibodies}

The ANCA-associated vasculitides, WG, CSS, and MPA, are grouped together because of common clinical features, pathologic involvement of the small vessels, similar responses to immunosuppressive interventions, and ANCA positivity (which is common but not universal).

Three indirect immunofluorescent staining patterns, cytoplasmic ANCA (C-ANCA), perinuclear ANCA (P-ANCA), and atypical ANCA are described. Each pattern is associated with antibodies against intracellular antigen(s) found in neutrophils and monocytes (Figure 2). C-ANCA is primarily associated with antibodies directed against proteinase 3 (PR3), which is found in azurophilic granules. The P-ANCA pattern is associated with antibodies directed against a wide variety of intracellular antigens; it is most commonly associated with myeloperoxidase (MPO), which is also found in azurophilic granules.

The sensitivity, specificity, and positive predictive value (PPV) of C-ANCA (or anti-PR3) for WG and P-ANCA (or anti-MPO) for MPA, CSS, and idiopathic pauci-immune RPGN are critical in determining their diagnostic utility (13-15). If these tests are not applied selectively to high-risk populations, then the PPV of the testing declines. Mandl and colleagues (4) demonstrated that when clinical guidelines were used to identify patients at higher risk for an ANCA-associated vasculitis, the PPV of the tests increased without reducing sensitivity. Although ANCA testing alone or PR3 and MPO ELISA testing alone are used by many centers as their initial screening test, the combination of ANCA indirect immunofluorescent testing plus ELISA testing maximizes their sensitivity $(16,17)$.

With the caveats noted previously, C-ANCA is highly sensitive $(90-95 \%)$ in active, systemic WG, with a specificity of approximately $90 \%$ (18). In the proper clinical setting (i.e., with a very high pretest probability of disease), a positive C-ANCA/ anti-PR3 has sufficient PPV that biopsy may be deferred. On the other hand, a positive P-ANCA lacks sensitivity and provides 


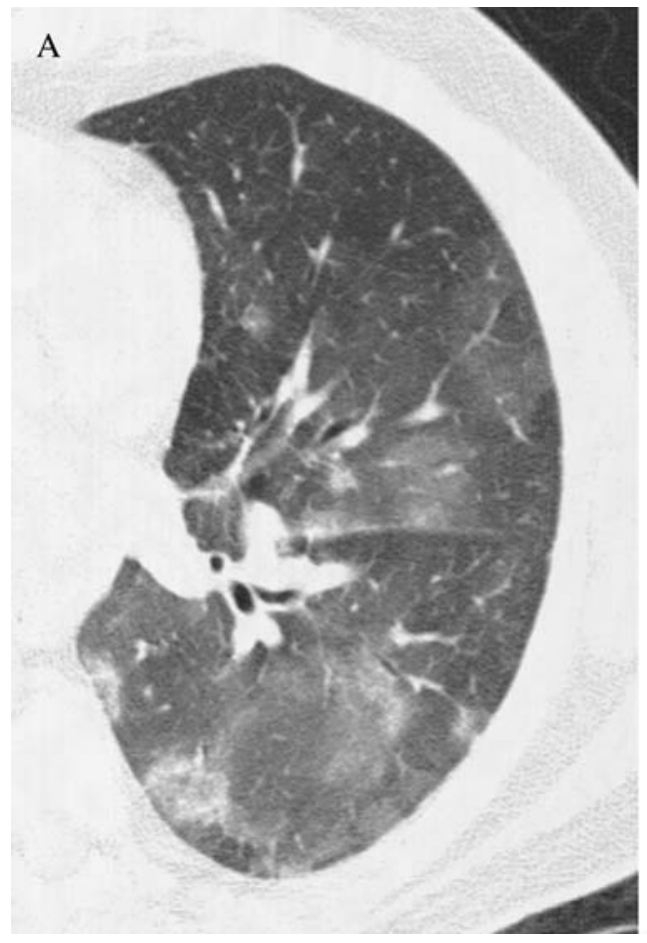

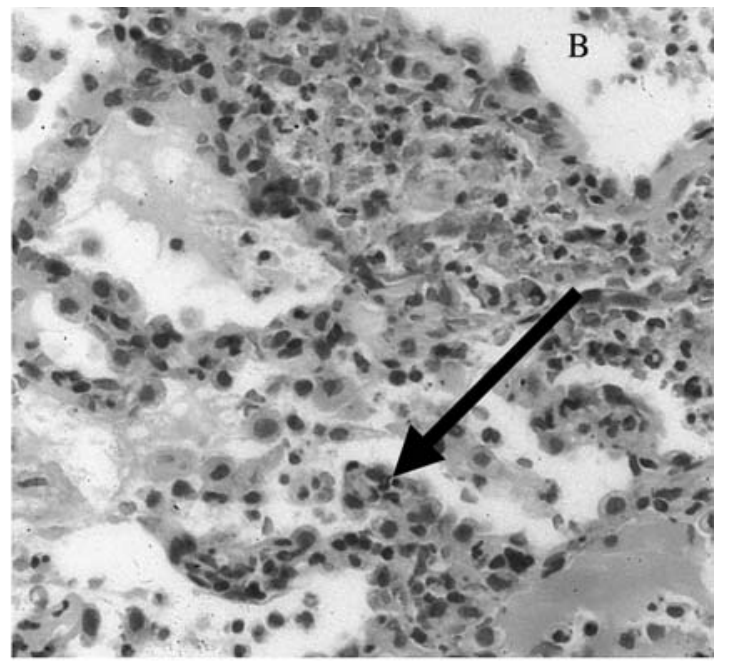

Figure 1. (A) High-resolution computed tomographic image of diffuse alveolar hemorrhage. The general pattern is that of patchy ground glass attenuation with or without consolidation. (B) On surgical lung biopsy, the histopathology of pulmonary capillaritis notes infiltration and expansion of the alveolar septae by degenerating neutrophils (arrow). Radiographic image courtesy of David A. Lynch, M.D.; pathologic image courtesy of Carlyne D. Cool, M.D. no more than suggestive evidence of CSS, MPA, or idiopathic pauci-immune RPGN (19-21) because it can be found in a wide variety of settings, including rheumatoid arthritis and Goodpasture's syndrome $(22,23)$.

Considerable attention has been focused on the role of a rising ANCA titers in predicting relapse in patients with vasculitis.

\section{TABLE 2. CAUSES OF DIFFUSE ALVEOLAR HEMORRHAGE}

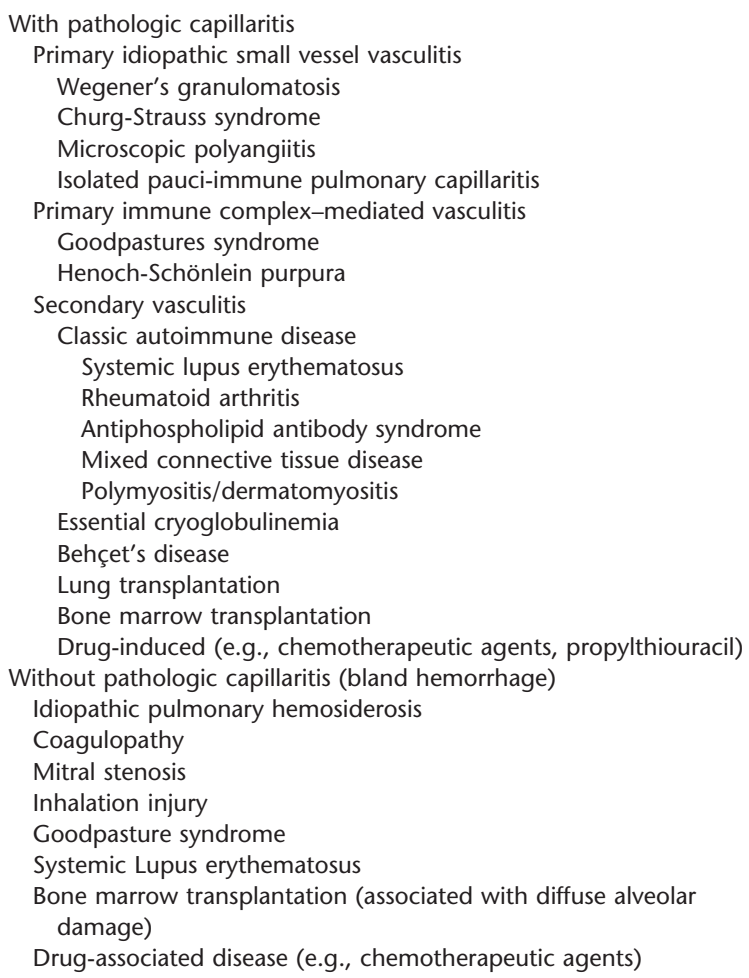

The current data suggest that there is insufficient sensitivity and specificity of an isolated rise in ANCA titer to accurately predict disease relapse in WG or other vasculitis $(24,25)$.

\section{Other Laboratories}

Culture of blood and other affected organs (when applicable) must be obtained to exclude infection. Routine laboratories (complete blood count with differential, chemistries, liver tests, blood urea nitrogen, and creatinine) should be obtained; however, the findings are generally nonspecific. An elevated erythrocyte sedimentation rate and $\mathrm{C}$-reactive protein are expected in active vasculitis but lack specificity. Urinalysis should be obtained in all patients, with the microscopic examination performed on a fresh sample (before red cell casts or other diagnostic features degenerate) by personnel skilled in its interpretation. Proteinuria and microscopic hematuria are common early findings in WG and MPA. Anti-glomerular basement membrane antibodies should be obtained in all patients with pulmonary hemorrhage or a pulmonary-renal syndrome and when present are indicative of Goodpasture's syndrome. Antinuclear antibodies and rheumatoid factor may be positive in primary vasculitis, although high titers and disease-specific antibodies, such as dsDNA, SS-A/SS-B, anti-RNP, and anti-JO-1, favor a connective tissue disease. IgE should be obtained when CSS is being considered. Complement (C3 and $\mathrm{C} 4$ ) should be obtained whenever SLE is in the differential.

\section{Radiographic Imaging}

The plain chest radiograph and computed tomography scanning of the chest often show abnormalities even in the absence of clinically significant symptoms. These findings are generally nonspecific. Cavities, nodules, and diffuse ground glass opacification when DAH is a possibility should raise the suspicion of vasculitis. The finding of adenopathy is not common and is more suggestive of infection or malignancy. 

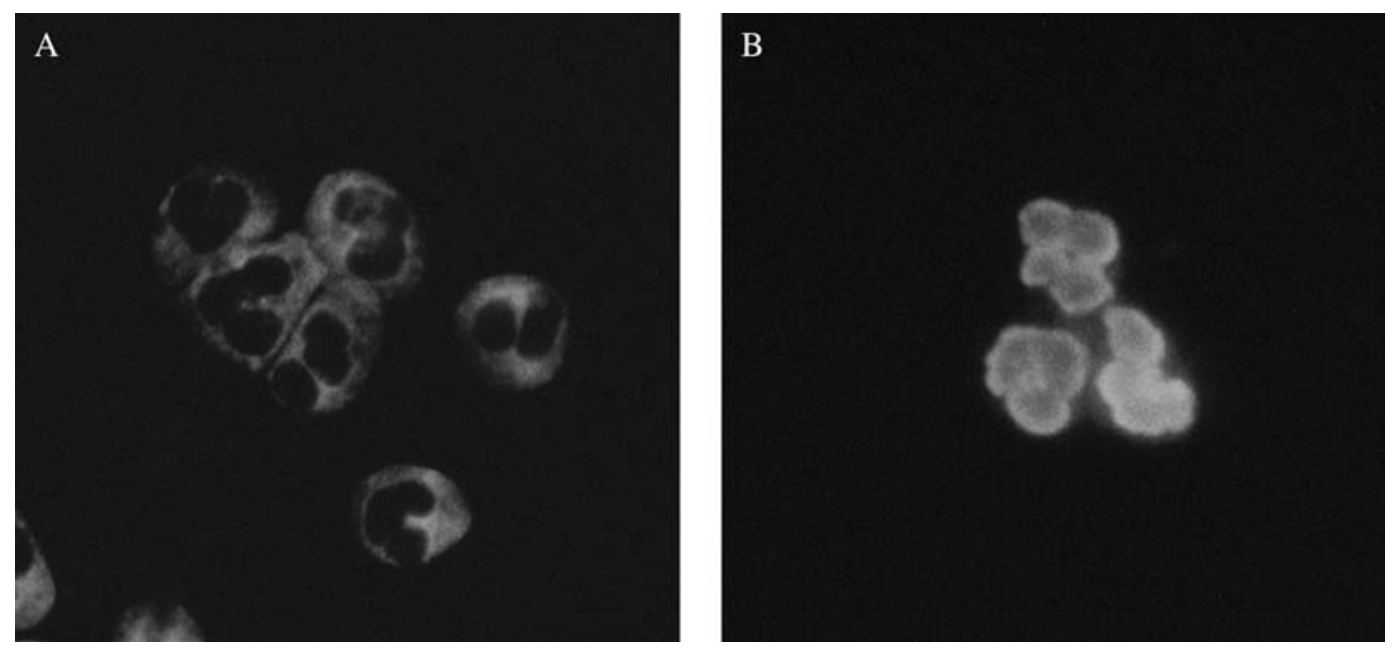

Figure 2. Indirect immunofluorescence staining for antineutrophil cytoplasmic antibodies (ANCA). ( $A$ ) The granular cytoplasmic staining pattern of C-ANCA. (B) The perinuclear pattern of P-ANCA. Images courtesy of Ron Harbeck, Ph.D.

\section{Bronchoscopy}

Bronchoscopy is used primarily to assess for infection and alveolar hemorrhage. However, pulmonary eosinophilia found on BAL or endobronchial lesions amenable to biopsy can be useful. Only rarely can one make a positive pathologic diagnosis of pulmonary vasculitis on transbronchial biopsy (26).

\section{Diagnostic Biopsy}

Although a confident diagnosis may occasionally be made without tissue, diagnostic biopsy remains the bedrock of diagnosis. Diagnostic tissue may infrequently be obtained from easily accessible sites, such as skin or upper airway lesions. Percutaneous renal biopsy is commonly performed during the evaluation of an acute glomerulonephritis. Although features specific for vasculitis (e.g., granulomatous inflammation or necrotic vessels) are rarely found, the finding of a focal, segmental necrotizing glomerulonephritis without immune deposits (pauci-immune) generally reflects a systemic vasculitis (27-29). It is important that in addition to conventional histopathology, immunofluorescence (and electron microscopic when appropriate) studies be performed. The presence of characteristic immunofluorescence patterns, such as IgA deposition in Henoch-Schönlein purpura, linear IgG deposition in Goodpasture's syndrome, and irregular immunoglobulin and complement deposition in SLE, help provide a specific diagnosis. When the lung is clinically involved, surgical lung biopsy almost always provides definitive pathologic evidence. If obtained, the clinician, surgeon, and pathologist must coordinate the management of the sample and collect tissue in saline for culture, frozen tissue for immunofluorescence, and formalin-fixed tissue for standard hematoxylin and eosin staining.

\section{SPECIFIC CLINICAL DISORDERS}

\section{WG}

WG is the most common of the ANCA-associated vasculitides. It is clinically characterized by the triad of (1) upper airway disease, (2) lower respiratory tract disease, and (3) glomerulonephritis (Table 3 ). The complete triad is frequently not present at initial presentation. Although 80 to $90 \%$ of patients ultimately develop renal disease, as few as $40 \%$ have renal involvement at first presentation $(27,30,31)$. Constitutional symptoms and ocular, skin, musculoskeletal, and central and peripheral nervous system disease are also relatively common. An abnormal chest radiograph is especially common when compared with the other vasculitides. Potential findings include alveolar, mixed, or inter- stitial infiltrates and nodular or cavitary disease $(8,9)$. A positive C-ANCA or anti-PR3 is found in 85 to $95 \%$ of active, systemic disease but is less frequently seen (60-65\% sensitive) in organlimited disease and is even less common (40\% sensitive) in remissions $(14,24,32,33)$. Its specificity is approximately $90 \%$. Pathologically, WG is characterized by a necrotizing vasculitis of the small and medium vessels, granulomatous inflammation, and geographic parenchymal necrosis (Figure 3) (34, 35). Prognostically, poor outcomes correlate with advanced age, more severe renal impairment, alveolar hemorrhage, and anti-PR3 positivity (36-38).

\section{CSS}

Although CSS is also an ANCA-associated vasculitis, its clinical presentation is generally distinct from that seen with WG, MPA, or idiopathic pauci-immune pulmonary capillaritis. It is generally considered when other eosinophilic lung diseases (e.g., chronic eosinophilic pneumonia) are in the differential or when patients with difficult-to-control asthma develop significant cardiac, gastrointestinal (GI), or neurologic disease. The syndrome is characterized by a triad of (1) asthma, (2) hypereosinophilia, and (3) necrotizing vasculitis. There is also a three-phase presentation with an initial atopy/sinusitis/asthma phase, followed by an eosinophilic phase, and then the vasculitic phase. Although pulmonary hemorrhage and glomerulonephritis may occur, they are much less common than in the other small-vessel vasculitides (Table 4)

TABLE 3. CLINICAL FEATURES OF WEGENER'S GRANULOMATOSIS

Clinical Manifestations Frequency (\%)

Pulmonary (cough, hemoptysis, dyspnea, chest pain)

Upper airway (epistaxis, sinusitis, rhinorrhea, otitis,

hearing impairment, ear pain, destructive

lesions/bony deformities ulcerations)

Tracheobronchial (subglottic stenosis, bronchial stenosis, endobronchial lesion)

Renal/glomerulonephritis

Cutaneous (purpura, ulcers, vesicles, or nodules)

Musculoskeletal (arthralgias, myalgias, arthritis)

Ocular (conjunctivitis, uveitis, episcleritis, scleritis, proptosis)

Constitutional (fever, weight loss, arthralgias, malaise)

Nervous system (peripheral, central, headache)

Cardiac (coronary vasculitis, pericarditis)
70-95

70-95

10-55

50-85

45-60

$30-70$

25-55

$15-45$

10-30

5-15 

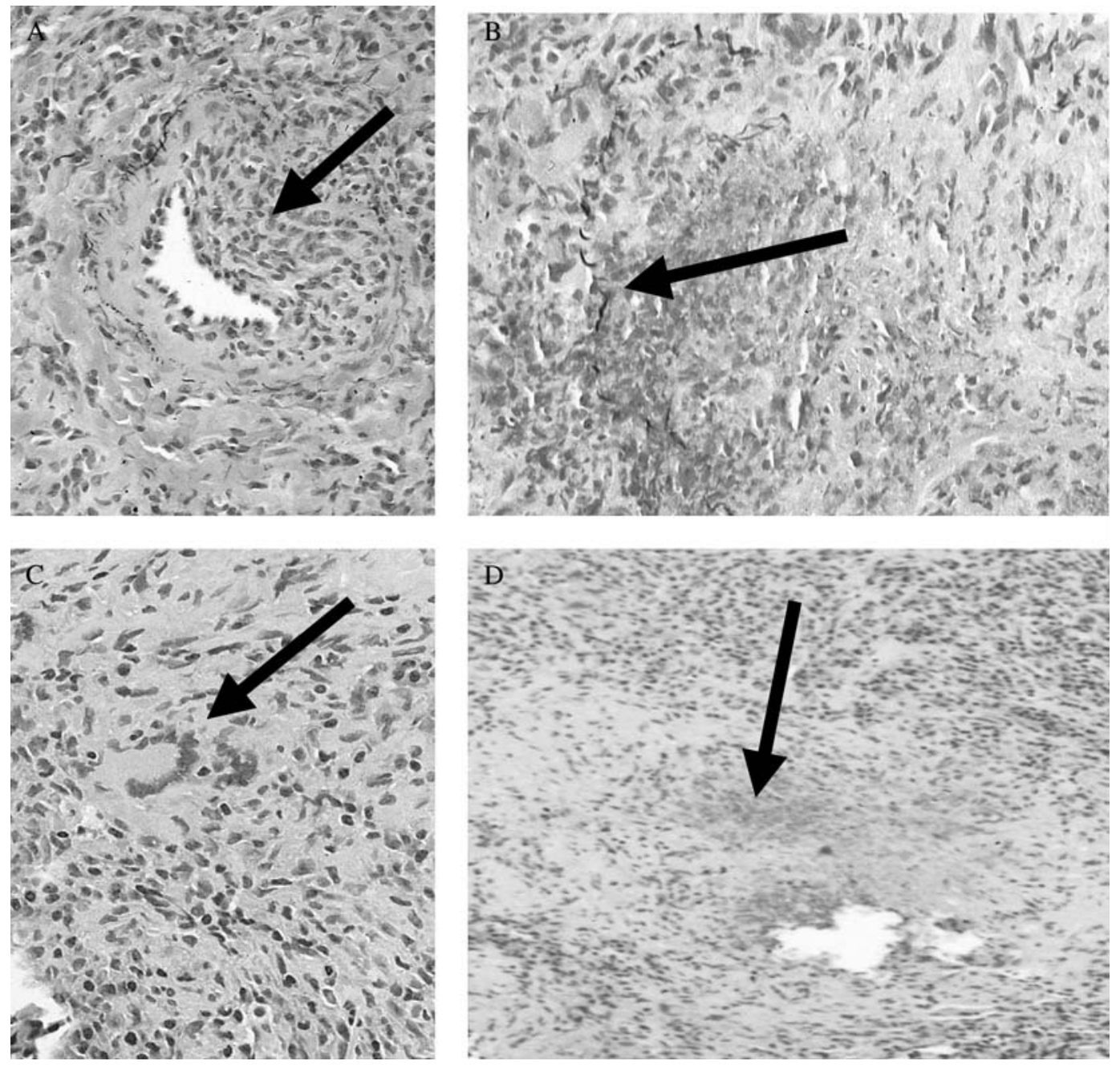

Figure 3. Histopathology of Wegener's granulomatosis. $(A)$ With vasculitis identified by eccentric inflammation (arrow) of a medium-sized artery with partial destruction of the elastic laminae on pentachrome staining. (B) With destructive vasculitis (arrow identifies remnants of elastic laminae). The artery is otherwise destroyed by an inflammatory process. (C) With granulomatous inflammation with a multinucleated giant cell (arrow). (D) With irregular, geographic necrosis with basophilic staining (arrow). Images courtesy of Carlyne D. Cool, M.D.
(39-42). Mortality and morbidity are often due to cardiac complications (up to one half of deaths), GI complications, or status asthmaticus and respiratory failure $(39,40,43)$. ANCA positivity is less frequently seen than in WG, with a positive P-ANCA (or anti-MPO) seen in 35 to $75 \%$ of patients with active disease (44). A positive C-ANCA has been described in up to $10 \%$ of patients. Pathologically, a necrotizing, small-vessel vasculitis and an eosinophil-rich cellular infiltrate with necrotizing granulomas are seen $(45,46)$.

Over the last several years, a number of case reports and case series have suggested an association between the use of leukotriene inhibitors and CSS (47). This led to the concern that leukotriene inhibition may promote the biologic conversion of severe asthma/atopic disease toward CSS (48). However, recent analysis of a number of patient cohorts and postmarketing surveillance data offer no compelling evidence of a pathogenic role for leukotriene receptor antagonists in the development of CSS (44, 49-51). Current data suggest that the appearance of disease is more likely related to the coincidental withdrawal of corticosteroids.

\section{Microscopic Polyangiitis}

Clinically, MPA is often heralded by a long prodromal phase of profound constitutional symptoms followed by the development of RPGN. It is a clinicopathologic syndrome with essentially universal glomerulonephritis, with pulmonary involvement seen in up to $30 \%$ of patients $(20,52,53)$. In patients who develop lung disease, DAH with pathologic capillaritis is the most common manifestation (53). Joint, skin, peripheral nervous system, and GI involvement are also relatively common (Table 5) (52). A positive P-ANCA is seen in 50 to $75 \%$ of patients, and anti-MPO is seen in 35 to $65 \%$ of patients, whereas a positive C-ANCA can be seen in 10 to $15 \%$ of patients. Pathologically, a focal, segmental necrotizing vasculitis and a mixed inflammatory infiltrate without granulomata are seen.

\section{TABLE 4. CLINICAL FEATURES OF CHURG-STRAUSS} SYNDROME

\begin{tabular}{lc}
\hline Clinical Manifestations & Frequency (\%) \\
\hline $\begin{array}{l}\text { Asthma } \\
\text { Constitutional (fever, chills, weight loss, }\end{array}$ & $98-100$ \\
$\quad$ arthralgias/myalgias) & $70-80$ \\
$\begin{array}{l}\text { Nervous system (mononeuritis multiplex, CNS, cerebral } \\
\quad \text { hemorrhage) }\end{array}$ & $50-80$ \\
$\begin{array}{l}\text { Cutaneous (purpura, urticaria, subcutaneous nodules, } \\
\quad \text { exanthem) }\end{array}$ & $50-80$ \\
Sinusitis & $20-70$ \\
Cardiac (pericarditis, heart failure, coronary vasculitis) & $35-50$ \\
Gl (diarrhea, Gl bleeding, colitis, pain) & $30-60$ \\
Renal (proteinuria, hematuria) & $10-50$ \\
\hline
\end{tabular}

Definition of abbreviations: CNS = central nervous system; GI = gastrointestinal. 
TABLE 5. CLINICAL FEATURES OF MICROSCOPIC POLYANGIITIS

\begin{tabular}{lc}
\hline Clinical Manifestations & Frequency (\%) \\
\hline Rapidly progressive glomerulonephritis & 100 \\
Pulmonary (hemorrhage, hemoptysis) & $10-30$ \\
Constitutional symptoms (fever, chills, weight loss, & \\
$\quad$ arthralgias/myalgias) & $70-80$ \\
Cutaneous (purpura, urticaria, subcutaneous nodules, & \\
$\quad$ exanthem) & $50-65$ \\
Nervous system (mononeuritis muliplex) & $15-50$ \\
Gl (pain, Gl bleeding, infarction, perforation) & $30-45$ \\
Ocular (conjunctivitis, uveitis) & $0-30$ \\
Cardiac & $10-20$ \\
Upper airway & $0-15$ \\
\hline
\end{tabular}

Definition of abbreviation: $\mathrm{Gl}=$ gastrointestinal.

\section{THERAPY}

Before the institution of immunosuppressive therapy, the mortality rate of patients with a systemic vasculitis was $75 \%$, with a median survival of 5 mo. The addition of lone corticosteroid therapy improved mortality at $1 \mathrm{yr}$ but had no impact at $3 \mathrm{yr}$ (there was significant steroid-associated mortality and morbidity). The 5-yr mortality remained at 50\%. The major breakthrough occurred when cyclophosphamide was added to corticosteroids, and this lowered the 5-yr mortality to $12 \%$. Despite this impressive progress, the survival of treated patients with a systemic vasculitis remains significantly lower than that of the general population (Figure 4) (54), and treatment-related complications are significant. Therefore, the goals of therapy in a systemic vasculitis are focused on the prevention of diseaserelated mortality and morbidity and on the minimization of treatment-related complications. Some general principles can be useful in outlining the approach to treatment.

\section{General Principles}

The backbone of therapy for the vasculitides is the early identification of disease followed by the rapid induction of disease control with immunosuppression. The severity of the disease generally dictates the intensity of the initial treatment, and the intensity of the treatment is often directly associated with the risk of complication. Because of this, the degree of immunosuppression is generally titrated so that disease control is obtained while minimizing the potential for adverse side effects. Therapy is often divided into two phases. An initial "remission-induction" phase is used to control active disease, and a "maintenance" phase, which uses less intensive therapy, is used to maintain disease remission while lowering the risk of adverse medicationrelated events.

Regardless of the phase of therapy, close disease-specific and drug-specific monitoring is necessary to identify disease activity (a flare), infection, or drug toxicity as early as possible. Clinicians should have a protocol for the prospective monitoring of side effects during remission-induction and maintenance therapy and should be familiar with the common toxicities associated with each drug. Finally, measures such as oxygen therapy, the treatment of comorbid diseases, vaccinations, physical and occupational therapy, nutrition, and psychosocial support should not be overlooked because they may help in minimizing the morbidity associated with these diseases and improving quality of life.

Treatment recommendations depend on an accurate determination of disease severity. Although severity and prognosis are dependent on a number of factors, the most important seem to be the severity of disease activity as measured by the number of organ systems involved, the degree of renal disease, and the presence of DAH. Based on this, the European Vasculitis Study Group (EUVAS) has devised a clinically useful grading system (Table 6) in which the patient's disease is categorized as (1) limited; (2) early, generalized; (3) active, generalized; (4) severe; and (5) refractory (55).

\section{Remission-Induction Therapy}

Limited disease. Limited disease refers to localized disease of the upper airway. These patients have no systemic symptoms, the function of end organs is not threatened, and there is no renal involvement. In this setting, therapy can often be limited to a single agent, such as corticosteroids, azathioprine, or methotrexate. Some authors have recommended trimethoprim/sulfamethoxazole (T/S) alone for this group (56), although it is not clear that this represents effective therapy. For clinically aggressive, though limited disease, therapy may need to be intensified along the lines outlined for early, generalized or active, generalized disease.

Early, generalized disease. Early, generalized disease is differentiated from active, generalized disease by the presence or absence of threatened organ function. Treatment recommendations for these two grades have traditionally been similar, with

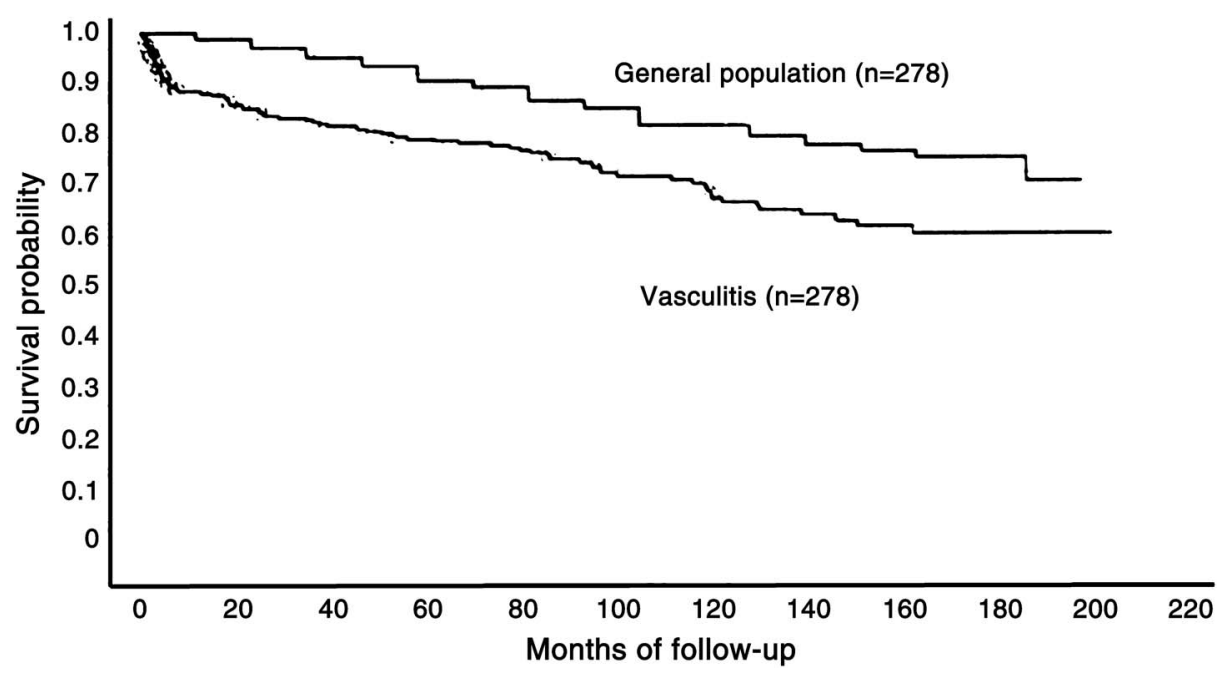

Figure 4. Survival curve of treated vasculitis. Reprinted by permission from Reference 54 . 
TABLE 6. EUVAS GRADING OF DISEASE SEVERITY

\begin{tabular}{|c|c|c|c|c|}
\hline Clinical Class & Constitutional Symptoms & Renal Function & $\begin{array}{l}\text { Threatened Vital } \\
\text { Organ Function }\end{array}$ & $\begin{array}{c}\text { Options for Induction } \\
\text { Therapy }\end{array}$ \\
\hline Limited & No & Creatinine $<120 \mu \mathrm{mol} / \mathrm{l}(1.4 \mathrm{mg} / \mathrm{dl})$ & No & $\begin{array}{l}\text { Corticosteroids OR } \\
\text { methotrexate OR } \\
\text { azathioprine }\end{array}$ \\
\hline Early generalized & Yes & Creatinine $<120 \mu \mathrm{mol} / \mathrm{l}(1.4 \mathrm{mg} / \mathrm{dl})$ & No & $\begin{array}{l}\text { Cyclophosphamide } \\
\text { OR methotrexate }+ \\
\text { corticosteroids }\end{array}$ \\
\hline Active generalized & Yes & Creatinine $<500 \mu \mathrm{mol} / \mathrm{l}(5.7 \mathrm{mg} / \mathrm{dl})$ & Yes & $\begin{array}{l}\text { Cyclophosphamide + } \\
\text { corticosteroids }\end{array}$ \\
\hline Severe & Yes & Creatinine $>500 \mu \mathrm{mol} / \mathrm{l}(5.7 \mathrm{mg} / \mathrm{dl})$ & Yes & $\begin{array}{l}\text { Cyclophosphamide }+ \\
\text { corticosteroids }+ \\
\text { plasma exchange }\end{array}$ \\
\hline Refractory & Yes & Any & Yes & $\begin{array}{l}\text { Consider investigational } \\
\text { agents }\end{array}$ \\
\hline
\end{tabular}

cyclophosphamide plus corticosteroids being the first-line therapy for both conditions. However, the Methotrexate versus Cyclophosphamide for "Early Systemic Disease" trial corroborated the findings of smaller studies in showing that methotrexate is equal to cyclophosphamide in the induction of disease remission in early generalized disease (57-59). Thus, cyclophosphamide and methotrexate are acceptable first-line therapy in this group, and, given the potentially more favorable side-effect profile, the combination of methotrexate plus corticosteroids is being increasingly used.

Active, generalized disease. Outcomes of patients with vasculitis were dismal before the landmark National Institutes of Health (NIH)-sponsored study demonstrating the effectiveness of oral cyclophosphamide plus oral corticosteroids for the treatment of WG (31). Since that time, cyclophosphamide plus corticosteroids has remained the principal first-line therapy for the treatment of active generalized vasculitis. Recent evidence suggests that pulsed intravenous cyclophosphamide may be as effective as oral cyclophosphamide and associated with fewer side effects. $(60,61)$ However, the Daily Oral versus Pulse Cyclophosphamide for Renal Vasculitis trial undertaken by EUVAS comparing the efficacy of pulsed, intravenous cyclophosphamide and oral, continuous cyclophosphamide has not been published, and the question remains unanswered.

Severe disease. Severe disease is defined by the functional impairment of critical organs, such as severe renal disease (creatinine $>5.7 \mathrm{mg} / \mathrm{dl}$ ), DAH, or other life-threatening disease. The management of these patients has been the subject of some debate; however, recent studies suggest that they should receive a combination of cyclophosphamide, corticosteroids, and plasma exchange therapy. The addition of plasma exchange therapy to the standard cyclophosphamide + corticosteroid regimen has been shown to be superior to high-dose, pulsed, intravenous steroids at restoring renal function in patients with severe renal impairment (62-67). On the basis of several case reports and a case series, this strategy may be effective for the treatment of DAH (66). Additional therapy, described in a case report, for patients with intractable DAH include activated human factor VII, which was used to induce hemostasis (68). Extracorporal membrane oxygenation has also been used at the case report level to "buy time" until other interventions have had a chance to work (69).

Refractory disease. Patients who have not responded to the aggressive use of cytotoxic agents, high-dose corticosteroids, or plasma exchange are deemed to have refractory disease. For this group, one must consider the use of novel or experimental agents. Treatments such as intravenous immunoglobulin, anti- tumor necrosis factor (TNF)- $\alpha$ therapy with infliximab, T-cell depletion therapy with antithymocyte globulin, and B-cell depletion therapy with rituximab have been used.

Several small studies have examined the efficacy of the anti-TNF- $\alpha$ therapy infliximab in inducing disease remission in refractory disease (70-74). The largest study found that infliximab was effective at inducing remission in $88 \%$ of patients. However, high rates of severe infection (21\%) and disease relapse $(20 \%)$ have limited enthusiasm for this approach. An EUVAS-sponsored open-label study of 15 patients with refractory WG treated with antithymocyte globulin found that 13 out of 15 patients achieved partial (9/15) or complete disease remission (4/15). Two patients died after the first dose (by pulmonary hemorrhage and infection) (75), and additional nonfatal complications, including serum sickness, have limited the appeal of this approach. Rituximab is a monoclonal anti-CD20 antibody that targets a subset of B lymphocytes. In a recent series of 11 patients with active ANCA-associated vasculitis, rituximab was used to treat patients who had received maximal doses or had other contraindications to cyclophosphamide therapy. Remission was induced in all 11 patients, and ANCA titers became undetectable in eight patients (76).

\section{Maintenance Therapy}

Maintenance therapy used to preserve control of disease requires less immunosuppression and should be associated with fewer and less severe adverse effects. After the induction of clinical remission with an agent such as cyclophosphamide, patients are generally converted to azathioprine or methotrexate. The large, multicenter, randomized Cyclophosphamide versus Azathioprine for Remission in Generalized Vasculitis (CYCAZAREM) trial confirmed the utility of azathioprine in maintaining disease control in patients who had achieved disease remission with cyclophosphamide (77). Methotrexate represents the best studied alternative and seems to have similar efficacy to azathioprine $(57,58,78)$. As with all cytotoxic agents, these agents must be introduced with gradual dose escalation and drug-specific monitoring to identify adverse effects as early as possible. Additional agents that have been used in selected patients include mycophenolate mofetil (MMF), leflunomide, and cyclosporine.

MMF is used primarily for immunosuppression in transplant patients and suppresses T and B lymphocytes. A 2004 study of MMF for remission maintenance after remission induction by cyclophosphamide plus prednisone was conducted at the NIH (79). Although the drug was relatively well tolerated, there was a relapse rate of $43 \%$ (6/14 patients). This was in contrast to an earlier study of MMF for remission maintenance that had 
identified only a $9 \%$ relapse rate (1/11 patients) (80). The much larger IMPROVE trial being conducted by EUVAS will directly compare the efficacy of MMF to azathioprine for remission maintenance. Leflunomide is a new immunosuppressive agent that targets primarily T cells. A phase II study of 20 patients found the drug to be relatively well tolerated in patients with WG when used for remission maintenance, with one major and eight minor disease relapses occurring over the course of the study (mean follow-up of $1.75 \mathrm{yr}$ ) (81). Despite the theoretic benefits of blocking TNF- $\alpha$ in the maintenance of disease remission, the Wegener's Granulomatosis Etanercept Trial demonstrated that etanercept was not effective for the maintenance of disease remission (82). In fact, the trial was stopped early when no differences were seen between experimental and controls groups in the rates of sustained remission, periods of low-level disease activity, the time required to achieve remission, and the rates of disease flare.

The timing of transition from the induction agent to maintenance therapy has been a subject of debate. Many physicians argue that patients should have 12 mo of induction therapy, whereas others argue for using clinical evidence of disease activity as the chief determinant of transition. The primary results of the CYCAZAREM trial demonstrated that patients with active generalized vasculitis may be transitioned from the remission induction phase with oral cyclophosphamide to the remission maintenance phase with azathioprine once a clinical remission (using defined criteria) has been induced. In this study, that meant that the transition to maintenance therapy occurred generally within 3 to $6 \mathrm{mo}$, with no increase in the rate of relapse, disease activity score, or change in renal function (77).

In the absence of a disease flare, maintenance therapy is generally continued for 12 to $18 \mathrm{mo}$. A longer duration of therapy should be considered for patients at high risk for relapse. The EUVAS-sponsored REMAIN trial (Randomized Trial of Prolonged Remission-Maintenance Therapy in Systemic Vasculitis) is underway and may answer some of the questions regarding duration of maintenance therapy by comparing the effects of low-dose prednisolone and azathioprine in patients treated for 24 or 48 mo after the onset of therapy. Relapse rate, cumulative morbidity scores, decline in renal function, and adverse-effects of therapy will be evaluated (83).

Another point of controversy has been the use of T/S (84, 85 ) and the reduction of nasal Staphylococcus aureus carriage in the therapy of ANCA-associated vasculitis $(86,87)$ Studies have demonstrated a reduced frequency of disease relapse in patients who are maintained on T/S compared with those without (85). Additional work suggests that this is related to the eradication of $S$. aureus nasal carriage $(86,87)$. The EUVAS-sponsored Placebo-controlled Trial of Nasal Mupirocin for the Prevention of Relapse, in which patients are randomized to eradication of nasal $S$. aureus with topical mupirocin or placebo, may answer the question. Regardless of the results of this study, T/S should be considered for Pneumocystis carinii prophylaxis in patients maintained on cyclophosphamide or other aggressive immunosuppression regimens barring a sulfa allergy or other contraindication.

\section{MONITORING FOR COMPLICATIONS AND DISEASE RELAPSE}

Monitoring for complications is necessary to minimize the morbidity and mortality of any of the vasculitides and their therapies. Patients with clinical deterioration raise a differential diagnosis of (1) infection, (2) drug toxicity, (3) disease relapse, or (4) a new, unrelated problem.

Infection is a major contributor to morbidity and mortality, often mimics a disease flare, and may present with atypical fea- tures. Up to $10 \%$ or more of patients with vasculitis treated with cyclophosphamide may develop clinically important infections (e.g., sepsis, pneumonia) even in the absence of drug-induced leucopenia (88). Patients maintained on a combination of highdose glucocorticoids and cytotoxic therapy are at especially high risk. Direct drug toxicity is also relatively frequent and clinically important. In patients with WG who are treated with cyclophosphamide, up to $12 \%$ may develop cystitis, $8 \%$ may develop myelodysplastic syndrome, and 5\% may develop solid malignancy (89).

Approximately $50 \%$ of patients with ANCA-associated vasculitis suffer one or more disease flares in spite of active therapy. Relapse is more common among patients with WG (40-65\%) and less common among patients with CSS $(15-25 \%)(54,90)$. Such flares may present with clinical manifestations similar to those seen at the time of the original diagnosis or with new signs, symptoms, and previously unaffected organs involved. In general, disease relapse requires reinduction-remission therapy. Although disease relapse is a clinical diagnosis, a recent study applying a proteomic approach to identifying remission in $\mathrm{WG}$ suggests that serum markers may one day permit accurate discrimination between quiescent and active disease (91).

\section{CONCLUSIONS}

Despite the considerable advances made in the diagnosis and management of the small-vessel vasculitides, the morbidity and mortality of these disorders remains high. An approach focused on early diagnosis using the identification of common clinical scenarios and aggressive early treatment minimizes diseaserelated mortality and irreversible damage. Although the results of a number of new treatment trials may alter specific treatment choices, the overall goals of therapy remain the same. The choice of therapy to induce remission should be determined by the severity of disease at presentation or relapse, with the maintenance regimen chosen to control disease and minimize treatment-related complications. Regular monitoring for disease activity (particularly in patients with an increased risk of relapse) and medication toxicity (direct and indirect) is required to minimize morbidity and improve long-term outcome.

Conflict of Interest Statement: K.K.B. does not have a financial relationship with a commercial entity that has an interest in the subject of this manuscript.

\section{References}

1. Cotch MF, Hoffman GS, Yerg DE, Kaufman GI, Targonski P, Kaslow RA. The epidemiology of Wegener's granulomatosis: estimates of the five-year period prevalence, annual mortality, and geographic disease distribution from population based data sources. Arthritis Rheum 1996; 39:87-92.

2. Gonzalez-Gay MA, Garcia-Porrua C. Systemic vasculitis in adults in northwestern Spain, 1988-1997: clinical and epidemiologic aspects. Medicine 1999;78:292-308.

3. Haugeberg G, Bie R, Bendvold A, Larsen AS, Johnsen V. Primary vasculitis in a Norwegian community hospital: a retrospective study. Clin Rheumatol 1998;17:364-368.

4. Mandl LA, Solomon DH, Smith EL, Lew RA, Katz JN, Shmerling RH. Using antineutrophil cytoplasmic antibody testing to diagnose vasculitis: can test-ordering guidelines improve diagnostic accuracy? Arch Intern Med 2002;162:1509-1514.

5. Zamora MR, Warner ML, Tuder R, Schwarz MI. Diffuse alveolar hemorrhage and systemic lupus erythematosus (SLE): clinical presentation, histology, survival and outcome. Medicine 1997;76:192-202.

6. Schwarz MI, Brown KK. Small vessel vasculitis of the lung. Thorax 2000;55:502-510.

7. Madaio MP, Harrington JT. The diagnosis of glomerular diseases. Arch Intern Med 2001;161:25-34.

8. Reuter M, Schnabel A, Wesner F, Tetzlaff K, Risheng Y, Gross WL, Heller M. Pulmonary Wegener's granulomatosis: correlation between high-resolution CT findings and clinical scoring of disease activity. Chest 1998;114:500-506. 
9. Cordier J-F, Valeyre D, Guillevin L, Loire R, Crechot J-M. Pulmonary Wegener's granulomatosis: a clinical and imaging study of 77 cases. Chest 1990;97:906-912.

10. Swerlick RA, Lawley TJ. Cutaneous vasculitis: its relationship to systemic disease. Med Clin North Am 1989;73:1221-1235.

11. Moore PM. Vasculitis of the central nervous system. Semin Neurol 1994; 14:307-312.

12. Guillevin L, Lhote F, Gherardi R. Polyarteritis nodosa, microscopic polyangiitis, and Churg-Strauss syndrome: clinical aspects, neurologic manifestations and treatment. Neurol Clin 1997;15:865-885.

13. Choi AM, Elbon CL, Bruce SA, et al. Messenger RNA levels of lung extracellular matrix proteins during ozone exposure. Lung 1994;172: 15-30.

14. Cohen-Tervaert JW, van der Woude FJ, Fauci AS, Ambrus JL, Velosa J, Keane WF, Meijer S, van der Giessen M, HauwThe T, van der Hem GK, et al. Association between active Wegener's granulomatosis and anticytoplasmic antibodies. Arch Intern Med 1989;149:2461-2465.

15. Savige J, Gillis D, Benson E, et al. International Consensus Statement on Testing and Reporting of Antineutrophil Cytoplasmic Antibodies (ANCA). Am J Clin Pathol 1999;111:507-513.

16. Csernok E, Holle J, Hellmich B, et al. Evaluation of capture ELISA for detection of antineutrophil cytoplasmic antibodies directed against proteinase 3 in Wegener's granulomatosis: first results from a multicentre study. Rheumatology (Oxford) 2004;43:174-180.

17. Russell KA, Wiegert E, Schroeder DR, et al. Detection of anti-neutrophil cytoplasmic antibodies under actual clinical testing conditions. Clin Immunol 2002;103:196-203.

18. Boomars KA, Wagenaar SS, Mulder PG, et al. Relationship between cells obtained by bronchoalveolar lavage and survival in idiopathic pulmonary fibrosis. Thorax 1995;50:1087-1092.

19. Hagen EC, Daha MR, Hermans J, et al. Diagnostic value of standardized assays for anti-neutrophil cytoplasmic antibodies in idiopathic systemic vasculitis. EC/BCR Project for ANCA Assay Standardization. Kidney Int 1998;53:743-753.

20. Guillevin L, Durand-Gasselin B, Cevallos R, Gayraud M, Lhote F, Callard P, Amouroux J, Casassus P, Jarrousse B. Microscopic polyangiitis. Arthritis Rheum 1999;42:421-430.

21. Gross WL. Antineutrophil cytoplasmic autoantibody testing in vasculitides. Rheum Dis Clin North Am 1995;21:987-1011.

22. Mulder AH, Horst G, van Leeuwen MA, Limburg PC, Kallenberg CG. Antineutrophil cytoplasmic antibodies in rheumatoid arthritis: characterization and clinical correlations. Arthritis Rheum 1993;36:1054-1060.

23. Schnabel A, Csernok E, Isenberg DA, Mrowka C, Gross WL. Antineutrophil cytoplasmic antibodies in systemic lupus erythematosus: prevalence, specificities, and clinical significance. Arthritis Rheum 1995;38: 633-637.

24. Kerr GS, Fleisher TA, Hallahan CW, Leavitt RY, Fauci AS, Hoffman GS. Limited prognostic value of changes in antineutrophil cytoplasmic antibody titers in patients with Wegener's granulomatosis. Adv Exp Med Biol 1993;336:411-414.

25. Ara J, Mirapeix E, Rodriguez R, et al. Relationship between ANCA and disease activity in small vessel vasculitis patients with anti-MPO ANCA. Nephrol Dial Transplant 1999;14:1667-1672.

26. Schnabel A, Holl-Ulrich K, Dalhoff K, et al. Efficacy of transbronchial biopsy in pulmonary vaculitides. Eur Respir J 1997;10:2738-2743.

27. Hoffman GS, Kerr GS, Leavitt RY, Hallahan CW, Lebovics RS, Travis WD, Rottem M, Fauci AS. Wegener's granulomatosis: an analysis of 158 patients. Ann Intern Med 1992;116:488-498.

28. Weiss MA, Crissman JD. Segmental necrotizing glomerulonephritis: diagnostic, prognostic, and therapeutic significance. Am J Kidney Dis 1985;6:199-211.

29. Hauer HA, Bajema IM, van Houwelingen HC, et al. Renal histology in ANCA-associated vasculitis: differences between diagnostic and serologic subgroups. Kidney Int 2002;61:80-89.

30. Anderson G, Coles ET, Crane M, Douglas AC, Gibbs AR, Geddes DM, et al. Wegener's granulomatosis: a series of 265 British cases seen between 1975 and 1985: a report by a sub-committee of the British Thoracic Society Research Committee. Q J Med 1992;83:427-438.

31. Fauci AS, Haynes BF, Katz P, Wolff SM. Wegener's granulomatosis: prospective clinical and therapeutic experience with 85 patients for 21 years. Ann Intern Med 1983;98:76-85.

32. Boomsma MM, Stegeman CA, van der Leij MJ, Oost W, Hermans J, Kallenberg CG, Limburg PC, Cohen Tervaert JW. Prediction of relapses in Wegener's granulomatosis by measurement of antineutrophil cytoplasmic antibody levels: a prospective study. Arthritis Rheum 2000;43:2025-2033.
33. Noille B, Specks U, Ludemann J, Rohrbach MS, DeRemee RA, Gross WL. Anticytoplasmic autoantibodies: their immunodiagnostic value in Wegener's Granulomatosis. Ann Intern Med 1989;111:28-40.

34. Travis WD, Hoffman GS, Leavitt RY, Pass HI, Fauci AS. Surgical pathology of the lung in Wegener's granulomatosis. Am J Surg Pathol 1991; 15:315-333.

35. Lie JT. Illustrated histopathologic classification criteria for selected vasculitic syndromes. Arthritis Rheum 1990;33:1074-1087.

36. Bligny D, Mahr A, Toumelin PL, et al. Predicting mortality in systemic Wegener's granulomatosis: a survival analysis based on 93 patients. Arthritis Rheum 2004:51:83-91.

37. Neumann I, Kain R, Regele H, et al. Histological and clinical predictors of early and late renal outcome in ANCA-associated vasculitis. Nephrol Dial Transplant 2005;20:96-104.

38. Gayraud M, Guillevin L, Cohen P, Lhote F, Cacoub P, Deblois P, Godeau B, Ruel M, Vidal E, Piontud M, et al. Treatment of good-prognosis polyarteritis nodosa and Churg-Strauss syndrome: comparison of steroids and oral or pulse cyclophosphamide in 25 patients. French Cooperative Study Group for Vasculitides. Br J Rheumatol 1997;36:12901297.

39. Guillevin L, Cohen P, Gayraud M, Lhote F, Jarrousse B, Casassus P. Churg-Strauss syndrome: clinical study and long-term follow-up of 96 patients. Medicine 1999;78:26-37.

40. Guillevin L, Guittard T, Bletry O, Godeau P, Rosenthal P. Systemic necrotizing angiitis with asthma: causes and precipitating factors in 43 cases. Lung 1987;165:165-172.

41. Lanham J, Elkon K, Pusey C, Hughes G. Systemic vasculitis with asthma and eosinophilia: a clinical approach to the Churg-Strauss syndrome. Medicine 1984;63:65-81.

42. Guillevin L, Houng Du LT, Godeau P, Jais P, Wechsler B. Clinical findings and prognosis of polyarteritis nodosa and Churg-Strauss angiitis: a study in 165 patients. Br J Rheumatol 1988;27:258-264.

43. Morgan JM, Raposo L, Gibson DG. Cardiac involvement in ChurgStrauss syndrome shown by electrocardiography. Br Heart J 1989; 62:462-466.

44. Keogh KA, Specks U. Churg-Strauss syndrome: clinical presentation, antineutrophil cytoplasmic antibodies, and leukotriene receptor antagonists. Am J Med 2003;115:284-290.

45. Churg J, Strauss L. Allergic granulomatosis, allergic angiitis, and periarteritis nodosa. Am J Pathol 1951;27:277-301.

46. Katzenstein AL. Diagnostic features and differential diagnosis of ChurgStrauss syndrome in the lung. A review. Am J Clin Pathol 2000;114: 767-772.

47. Wechsler ME, Finn D, Gunawardena D, Westlake R, Barker A, Haranath SP, Pauwels RA, Kips JC, Drazen JM. Churg-Strauss syndrome in patients receiving montelukast as treatment for asthma. Chest 2000; 117:708-713.

48. Weller PF, Plaut M, Taggart V, Trontell A. The relationship of asthma therapy and Churg-Strauss syndrome: NIH workshop summary report. J Allergy Clin Immunol 2001;108:175-183.

49. Jamaleddine G, Diab K, Tabbarah Z, et al. Leukotriene antagonists and the Churg-Strauss syndrome. Semin Arthritis Rheum 2002;31:218-227.

50. Coulter D. Pro-active safety surveillance. Pharmacoepidemiol Drug Saf 2000;9:273-280

51. Lilly CM, Churg A, Lazarovich M, et al. Asthma therapies and ChurgStrauss syndrome. J Allergy Clin Immunol 2002;109:S1-19.

52. Lhote F, Guillevin L. Polyarteritis nodosa, microscopic polyangiitis and Churg-Strauss syndrome. Semin Respir Crit Care Med 1998;19:27-45.

53. Akikusa B, Sato T, Ogawa M, Ueda S, Kondo Y. Necrotizing alveolar capillaritis in autopsy cases of microscopic polyangiitis: incidence, histopathogenesis and relationship with systemic vasculitis. Arch Pathol Lab Med 1997:121:144-149.

54. Gayraud M, Guillevin L, le Toumelin P, Cohen P, Lhote F, Casassus P, Jarrousse B. Long-term followup of polyarteritis nodosa, microscopic polyangiitis, and Churg-Strauss syndrome: analysis of four prospective trials including 278 patients. Arthritis Rheum 2001;44:666-675.

55. Jayne D. Evidence-based treatment of systemic vasculitis. Rheumatology (Oxford) 2000;39:585-595.

56. DeRemee RA. Wegener's granulomatosis. Ann Intern Med 1992;117: 619-620 (author reply: 620-611).

57. de Groot K, Muhler M, Reinhold-Keller E, et al. Induction of remission in Wegener's granulomatosis with low dose methotrexate. J Rheumatol 1998;25:492-495.

58. Langford CA, Talar-Williams C, Sneller MC. Use of methotrexate and glucocorticoids in the treatment of Wegener's granulomatosis: long-term renal outcome in patients with glomerulonephritis. Arthritis Rheum 2000;43:1836-1840. 
59. De Groot K, Rasmussen N, Bacon PA, et al. Randomized trial of cyclophosphamide versus methotrexate for induction of remission in early systemic antineutrophil cytoplasmic antibody-associated vasculitis. Arthritis Rheum 2005;52:2461-2469.

60. de Groot K, Adu D, Savage CO. The value of pulse cyclophosphamide in ANCA-associated vasculitis: meta-analysis and critical review. Nephrol Dial Transplant 2001;16:2018-2027.

61. Rihova Z, Jancova E, Merta M, et al. Daily oral versus pulse intravenous cyclophosphamide in the therapy of ANCA-associated vasculitis: preliminary single center experience. Prague Med Rep 2004;105:64-68.

62. Pusey CD, Rees AJ, Evans DJ, et al. Plasma exchange in focal necrotizing glomerulonephritis without anti-GBM antibodies. Kidney Int 1991;40: 757-763.

63. Guillevin L, Lhote F, Cohen P, Jarrousse B, Lortholary O, Genereau T, Leon A, Bussel A. Corticosteroids plus pulse cyclophosphamide and plasma exchanges versus corticosteroids plus pulse cyclophosphamide alone in the treatment of polyarteritis nodosa and Churg-Strauss syndrome patients with factors predicting poor prognosis: a prospective, randomized trial in sixty-two patients. Arthritis Rheum 1995;38:16381645.

64. Gaskin G, Pusey C. Plasmapheresis in antineutrophil cytoplasmic antibodyassociated systemic vasculitis. Ther Apher 2001;5:176-181.

65. Frasca GM, Soverini ML, Falaschini A, et al. Plasma exchange treatment improves prognosis of antineutrophil cytoplasmic antibody-associated crescentic glomerulonephritis: a case-control study in 26 patients from a single center. Ther Apher Dial 2003;7:540-546.

66. Klemmer PJ, Chalermskulrat W, Reif MS, et al. Plasmapheresis therapy for diffuse alveolar hemorrhage in patients with small-vessel vasculitis. Am J Kidney Dis 2003;42:1149-1153.

67. Cole E, Cattran D, Magil A, et al. A prospective randomized trial of plasma exchange as additive therapy in idiopathic crescentic glomerulonephritis. The Canadian Apheresis Study Group. Am J Kidney Dis 1992;20:261-269.

68. Henke D, Falk RJ, Gabriel DA. Successful treatment of diffuse alveolar hemorrhage with activated factor VII. Ann Intern Med 2004;140:493494.

69. Ahmed SH, Aziz T, Cochran J, et al. Use of extracorporeal membrane oxygenation in a patient with diffuse alveolar hemorrhage. Chest 2004; 126:305-309.

70. Lamprecht $\mathrm{P}$, Voswinkel J, Lilienthal T, et al. Effectiveness of TNF-a blockade with infliximab in refractory Wegener's granulomatosis. Rheumatology 2002;41:1303-1307.

71. Bartolucci P, Ramanoelina J, Cohen P, et al. Efficacy of the anti-TNFalpha antibody infliximab against refractory systemic vasculitides: an open pilot study on 10 patients. Rheumatology 2002;41:1126-1132.

72. Kleinert J, Lorenz M, Kostler W, et al. Refractory Wegener's granulomatosis responds to tumor necrosis factor blockade. Wien Klin Wochenschr 2004;116:334-338.

73. Arbach O, Gross WL, Gause A. Treatment of refractory Churg-StraussSyndrome (CSS) by TNF-alpha blockade. Immunobiology 2002;206: 496-501.

74. Booth A, Harper L, Hammad T, et al. Prospective study of TNFalpha blockade with infliximab in anti-neutrophil cytoplasmic antibodyassociated systemic vasculitis. J Am Soc Nephrol 2004;15:717-721.

75. Schmitt WH, Hagen EC, Neumann I, et al. Treatment of refractory Wegeners granulomatosis with antithymocyte globulin (ATG): an open study in 15 patients. Kidney Int 2004;65:1440-1448.

76. Keogh KA, Wylam ME, Stone JH, et al. Induction of remission by B lymphocyte depletion in eleven patients with refractory antineutrophil cytoplasmic antibody-associated vasculitis. Arthritis Rheum 2005;52: 262-268.

77. Jayne D, Rasmussen N, Andrassy K, et al. A randomized trial of maintenance therapy for vasculitis associated with antineutrophil cytoplasmic autoantibodies. N Engl J Med 2003;349:36-44.

78. Stone JH, Tun W, Hellman DB. Treatment of non-life threatening Wegener's granulomatosis with methotrexate and daily prednisone as the initial therapy of choice. J Rheumatol 1999;26:1134-1139.

79. Langford CA, Talar-Williams C, Sneller MC. Mycophenolate mofetil for remission maintenance in the treatment of Wegener's granulomatosis. Arthritis Rheum 2004;51:278-283.

80. Nowack R, Gobel U, Klooker P, et al. Mycophenolate mofetil for maintenance therapy of Wegener's granulomatosis and microscopic polyangiitis: a pilot study in 11 patients with renal involvement. J Am Soc Nephrol 1999;10:1965-1971.

81. Metzler C, Fink C, Lamprecht P, et al. Maintenance of remission with leflunomide in Wegener's granulomatosis. Rheumatology (Oxford) 2004;43:315-320.

82. Wegener's Granulomatosis Etanercept Trail (WGET) Research Group. Etanercept plus standard therapy for Wegener's granulomatosis. N Engl J Med 2005;352:351-361.

83. EUVAS Study Group, 2004 [cited October 14, 2005]. Available from: www.vasculitis.org.

84. DeRemee RA, McDonald TJ, Weiland LH. Wegener's granulomatosis: observations on treatment with antimicrobial agents. Mayo Clin Proc 1985;60:27-32.

85. Ohtake T, Kobayashi S, Honjou Y, Shirai T, Takayanagi S, Tohyama K, Tokura Y, Kimura M. Generalized Wegener's granulomatosis responding to sulfamethoxazole-trimethoprim monotherapy. Intern Med 2001;40:666-670.

86. Stegeman CA, Tervaert JW, Sluiter WJ, et al. Association of chronic nasal carriage of Staphylococcus aureus and higher relapse rates in Wegener's granulomatosis. Ann Intern Med 1994;120:12-17.

87. Stegeman CA, Tervaert JW, de Jong PE, et al. Trimethoprim-sulfamethoxazole for the prevention of relapses of Wegener's granulomatosis. $N$ Engl J Med 1996;335:16-20.

88. Bradley JD, Brandt KD, Katz BP. Infectious complications of cyclophosphamide treatment for vasculitis. Arthritis Rheum 1989;32:45-53.

89. Reinhold-Keller E, Beuge N, Latza U, DeGroot K, Rudert H, Nolle B, Heller M, Gross W. An interdisciplinary approach to the care of patients with Wegener's granulomatosis. Arthritis Rheum 2000; 43:1021-1032.

90. Gordon M, Luqmani RA, Adu D, Greaves I, Richards N, Michael J, Emery P, Howie AJ, Bacon PA. Relapses in patients with a systemic vasculitis. $Q J$ Med 1993;86:779-789.

91. Stone JH, Rajapakse VN, Hoffman GS, et al. A serum proteomic approach to gauging the state of remission in Wegener's granulomatosis. Arthritis Rheum 2005;52:902-910. 